\title{
GTO PWM Current Source Converter Array For Superconducting Magnetic Energy Storage
}

\author{
member Dehong Xu \\ (Zhejiang University, China) \\ student member Junpei Baba \\ (The University of Tokyo) \\ member \\ Eisuke Masada \\ (The University of Tokyo) \\ member \\ Hiroyuki Ohsaki \\ (The University of Tokyo)
}

\begin{abstract}
A novel multi modular GTO current source converter structure is presented to application to superconducting magnetic energy storage system. $\mathrm{N} \times \mathrm{N}$ converters are arranged in a array form. The GTO current source converter array with appropriate arrangement of modulation and carrier signals can output large power with high quality line current waveforms. With using of only $N$ transformers, $6 \mathrm{~N}^{2}$ pulse number converter performance is obtained. Only low switching of GTO is required since PWM is primarily used as a method to control flow of power instead of reducing harmonics. It is compared with conventional direct paralleled multi modular converter structure. The results of simulation are presented in this paper.
\end{abstract}

Key words: Multi modular Converters, PWM converters, High power converter, SMES, PWM

\section{Introduction}

High power converters with low harmonics are required for application in Superconducting Magnetic Energy Storage(SMES). GTOs are generally used because of high power. Switching frequency is restricted to a lower value. Multi converter modular combination structures have been used to reduce the harmonics and increase power capacity. [1] [2] Multi current source converter modular connecting structure can be classified as follows

- Method 1: AC sides of converter modular are paralleled through phase shifting transformers. DC side of converter modular are paralleled through current sharing inductors or seriesed directly.

- Method 2: AC sides of converter modular are directly connected with PWM carrier signal phases evenly shifted. [1] DC side of converter modular are paralleled through current sharing inductors, as shown in figure 1 .

Method 2 is more advantage than Method 1 since transformers are not needed. Harmonics reduction of Method 2 is based on equal distant phase shifting of multi carriers. However in this condition generally average voltage of DC side of converter modular are not equal while the switching frequency is as low as $150 \mathrm{~Hz}$. DC side voltage of a converter can be described as

$$
u_{d c}=Y_{a} u_{a}+Y_{b} u_{b}+Y_{c} u_{c}
$$

where $u_{a}, u_{b}$, and $u_{c}$ are input three phase voltage of converters, and $\mathrm{Y}_{\mathrm{a}}, \mathrm{Y}_{\mathrm{b}}$, and $\mathrm{Y}_{\mathrm{c}}$ are switch control functions of a converter. There are relationships between trilogic signal $Y_{a}, Y_{b}$, and $Y_{c}$, and bilogic signal $X_{a}$, $X_{b} \quad$ and $X_{c}$,i.e. $Y_{a}=\left(X_{a}-X_{b}\right) / 2$, $Y_{b}=\left(X_{b}-X_{c}\right) / 2$ and $Y_{c}=\left(X_{c}-X_{a}\right) / 2$ [1].It is assumed that three phase voltage are balanced. Carrier frequency $\omega_{s}$ is three times multiple of utility frequency $\omega$. In this time $Y_{a}, Y_{b}$, and $Y_{c}$ are balanced. $Y_{a}$ can be described as $\sum_{n=2 k+1}^{\infty} y_{n} \sin \left(n \omega t+\phi_{n}\right)$, where $\mathrm{k} \geq 0$. Then $\quad \mathrm{y}_{1}=\sqrt{3} \mathrm{x}_{1} / 2$ and $\cos \phi_{1}=\cos \left(\phi_{\mathrm{x}}+30^{\circ}\right)$, where $\mathrm{x}_{\mathrm{l}}$ and $\phi_{\mathrm{x}}$ is amplitude and phase angle of fundamental component of $X_{\mathrm{a}} . \quad X_{\mathrm{a}}=\operatorname{sign}\left[\mathrm{v}_{\mathrm{ma}}\left(\omega \mathrm{t}+\phi_{\mathrm{m}}\right)-\mathrm{v}_{\mathrm{c}}\left(\omega_{\mathrm{s}} \mathrm{t}+\phi_{\mathrm{s}}\right)\right]$ where $\operatorname{sign}(x)=1$ if $x \geq 0, \operatorname{sign}(x)=-1$ if $x<0$. $v_{m a}$ is the modulation wave of phase $A$ and $v_{c}$ is the carrier. The DC component of $u_{d c}$ can be described by

$$
\begin{aligned}
\mathrm{U}_{\mathrm{dc}} & =\frac{1}{2 \pi} \int_{0}^{2 \pi} \mathrm{u}_{\mathrm{dc}} \mathrm{d} \omega \mathrm{t}=\frac{3}{2 \pi} \int_{0}^{2 \pi} Y_{\mathrm{a}} \mathrm{u}_{\mathrm{a}} \mathrm{d} \omega \mathrm{t} \\
& =\frac{3}{2 \pi} \int_{0}^{2 \pi} \mathrm{U} \sin (\omega \mathrm{t}) \sum_{\mathrm{n}=2 \mathrm{k}+1}^{\infty} \mathrm{y}_{\mathrm{n}} \sin \left(\mathrm{n} \omega \mathrm{t}+\phi_{\mathrm{n}}\right) \mathrm{d} \omega \mathrm{t} \\
& =\frac{3 \mathrm{y}_{1} \mathrm{U} \cos \phi_{1}}{2} \\
& =\frac{3 \sqrt{3} \mathrm{U} \mathrm{x}_{1} \cos \left(\phi_{\mathrm{x}}+30^{\circ}\right)}{4}
\end{aligned}
$$




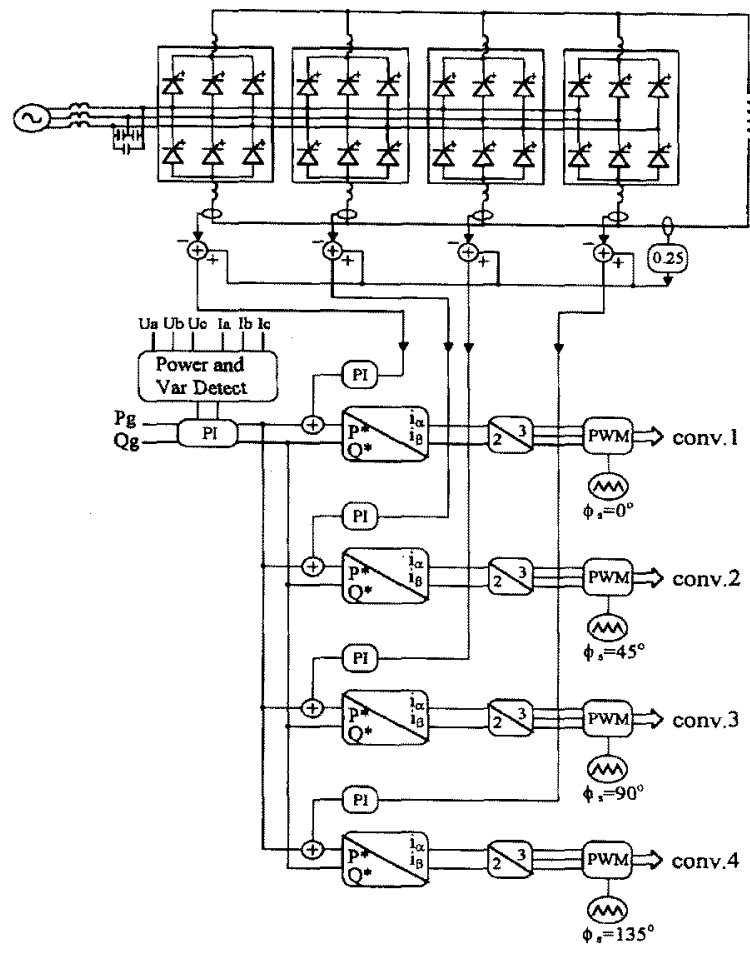

Figure 1: SMES using direct paralleled four converters

Figure 2 shows variation of $U_{d c}$ with changing of phase angle $\phi_{S}$ of the carrier. $\omega$ is utility frequency. The carrier frequency $\omega_{s}$ is selected to be $3 \omega$. For a given group three modulation signals

$$
\begin{aligned}
\mathrm{v}_{\mathrm{ma}} & =\mathrm{v}_{\mathrm{m}} \sin \left(\omega \mathrm{t}+\phi_{\mathrm{m}}\right) \\
\mathrm{v}_{\mathrm{mb}} & =\mathrm{v}_{\mathrm{m}} \sin \left(\omega \mathrm{t}+\phi_{\mathrm{m}}-120^{\circ}\right) \\
\text { and } \mathrm{v}_{\mathrm{mc}} & =\mathrm{v}_{\mathrm{m}} \sin \left(\omega \mathrm{t}+\phi_{\mathrm{m}}-240^{\circ}\right),
\end{aligned}
$$

converter DC side output $U_{d c}$ changes largely with the changing of the phase angle of the carrier.

Conventionally the amplitude $V_{m}$ and phase angle $\phi_{\mathrm{m}}$ of modulation waves are adjusted to make converter evenly sharing DC load current. At this time modulation signals of the paralleled converters become to be different. If there is no current sharing control, modulation signals for phase A of four paralleled converters are the same as shown in Fig.3(a). When a current sharing control is used, modulation signals for the paralleled converters differs as shown in Fig.3(b). Fig.2 is the result got from a case of direct paralleled four converters. As a result, harmonics cancellation originally expected can not be reached pronouncedly as shown in Fig. 4

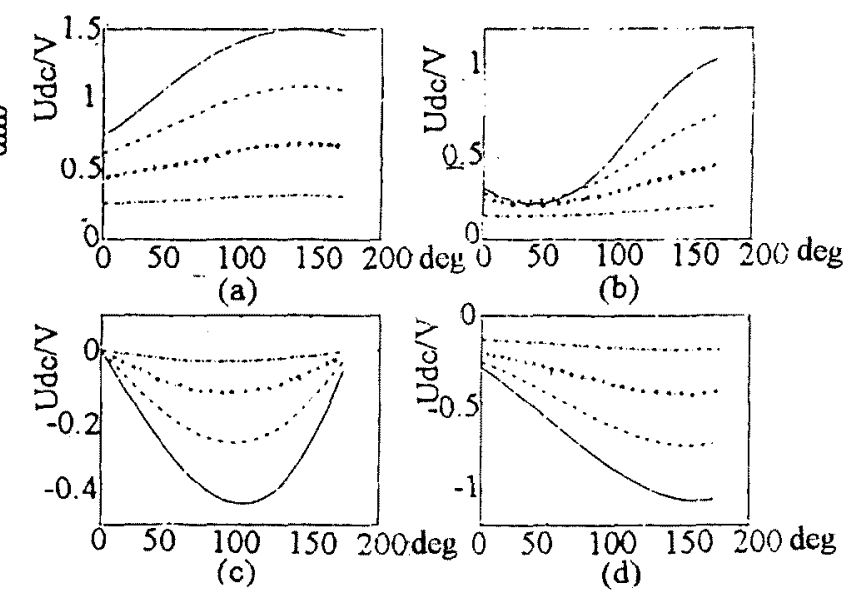

Figure 2: variation of $U_{d c} U$ caused by variation of carrier phase $\phi_{\mathrm{s}}$. Here - $: \mathrm{V}_{\mathrm{m}} / \mathrm{V}_{\mathrm{cm}}=1:--: \mathrm{V}_{\mathrm{m}} / \mathrm{V}_{\mathrm{cm}}$ $=0.75 ; \cdots: V_{\mathrm{m}} / \mathrm{V}_{\mathrm{cm}}=0.5 ; \cdots: \mathrm{V}_{\mathrm{m}} / \mathrm{V}_{\mathrm{cm}}=0.25$. (a)
$\phi_{\mathrm{m}}=0^{\circ}$;
(b) $\phi_{\mathrm{m}}=30^{\circ}$;
(c) $\phi_{\mathrm{m}}=60^{\circ}$;
(d) $\phi_{\mathrm{m}}=90^{\circ}$

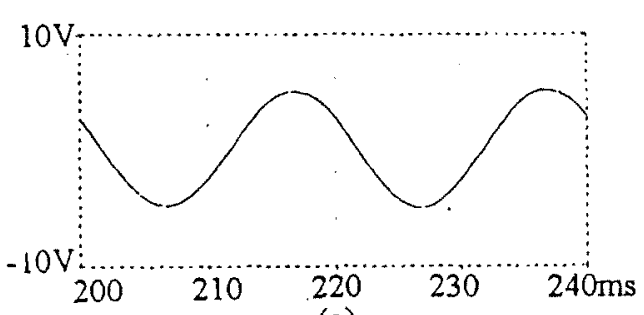

(a)

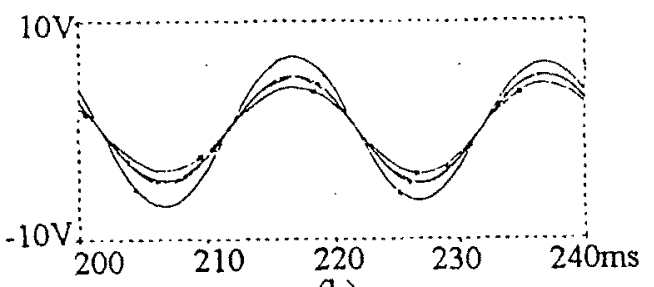

(b)

Figure 3: modulation signals for phase $A$ of direct paralleled four converters (a) without current sharing control (b) with current sharing control

\section{Converter array}

$\mathrm{N} \times \mathrm{N}$ number of converters are connected as shown in Fig.5. $\mathrm{N} \times \mathrm{N}$ converters arranged in a array form and connected in such a way that ac side of $\mathrm{N}$ number of converters in each row are paralleled and then connected to one phase shifting transformer, and dc side of $\mathrm{N}$ number of converters in each column serially connected and then connected to the load through a current sharing inductor. $\mathrm{N}$ transformers are used to generate evenly phase shifting isolated three phase voltage. The phase 
shift of consecutive two transformers is $\Delta \phi=60^{\circ} / \mathrm{N}$
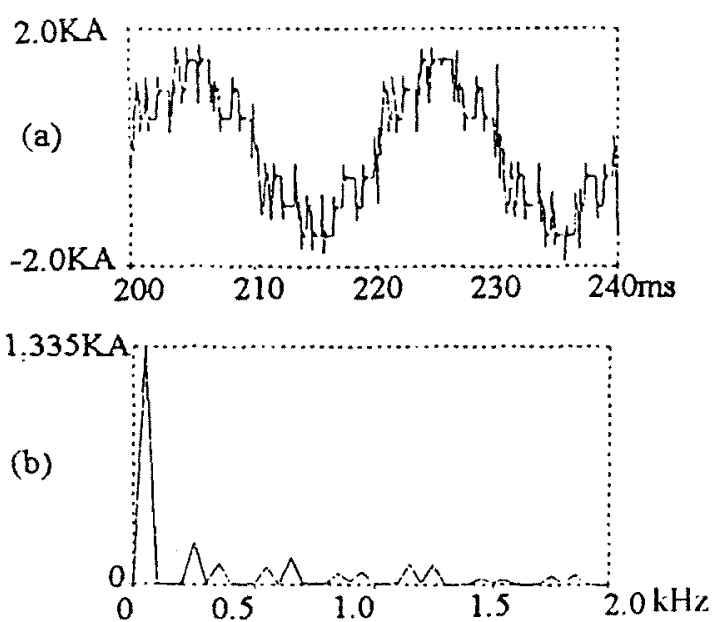

Figure 4: one phase current of direct paralleled four converters with current sharing control (a) one phase current (b) its harmonic spectrum

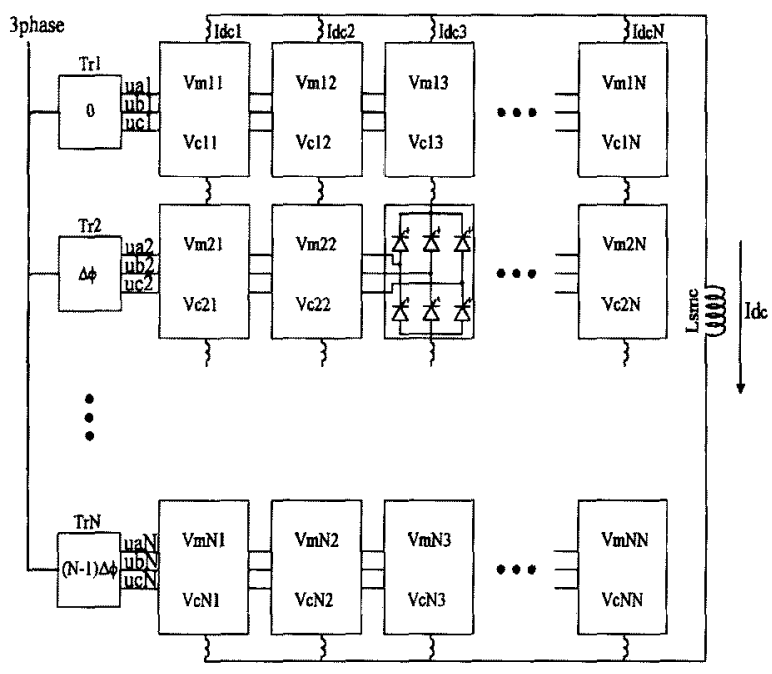

Figure 5: converter array

Therefore current harmonics less than $6 \mathrm{~N} \pm 1$ are completely eliminated. Each transformer is paralleled with $\mathrm{N}$ converters. A converter in $\mathrm{i}$ row and $\mathrm{j}$ column is marked as Conv $(i, j)$. Operation of $\operatorname{Conv}(i, j)$ is decided by its modulation signals and its carrier. Three phase modulation signals of a converter are balanced. The phase A modulation signal of $\operatorname{Con}(i, j)$ is selected as

$$
\mathrm{V}_{\mathrm{mij}}^{\mathrm{a}}=\mathrm{V}_{\mathrm{m}} \sin \left(\omega \mathrm{t}+\phi_{\mathrm{m}}+\beta_{\mathrm{i}, \mathrm{j}}\right)
$$

The carrier wave of Conv $(i, j)$ is defined

$$
V_{c i j}=V_{c}\left(\omega_{s} t+{ }_{\omega}^{\omega_{s}} \beta_{i, j}\right)
$$

$$
\beta_{i, j}=(i-1) \Delta \phi+[i+j-2]_{N} \Delta \psi
$$
where $V_{c}\left(\omega_{\mathrm{s}} t\right)$ is triangle carrier wave, and $\Delta \psi=\frac{\Delta \phi}{N}$. $[i+j-2]_{N}$ is defined as $(i+j-2) \bmod N$. With above mentioned modulation waves and carriers used, three phase ac current waveforms of converters in the same row are the same except for phase shift.

Phase A current of converter module Conv $(i, j), i_{a}^{(i, j)}$ is

$$
i_{a}^{(i, j)}=I_{d c j} Y_{a}^{(i, j)}=\frac{I_{d c}}{2 N}\left(X_{a}^{(i, j)}-X_{b}^{(i, j)}\right)
$$

Where it is assumed that DC side current $I_{d c}$ is evenly supported by $N$ paralleled output branches, i.e. $I_{d c j}=I_{d c} / N$. Phase A current of transformer $\mathrm{i}$ can be described by

$$
\mathrm{i}_{\mathrm{a}}^{(i)}=\sum_{j=1}^{N} \mathrm{i}_{\mathrm{a}}^{(i, j)}=\frac{\mathbb{I}_{d c}}{2 \mathrm{~N}}\left[\sum_{j=1}^{N} \mathrm{X}_{\mathrm{a}}^{(i, j)}-\sum_{j=1}^{N} X_{b}^{(i, j)}\right]
$$

Since $X_{a}^{(i, j)}=\operatorname{sign}\left(V_{m i j}-V_{c i j}\right), i_{a}^{(i)}$ can be expressed as

$$
\begin{aligned}
i_{a}^{(i)}= & I_{d c}\left(\sum _ { j = 1 } ^ { N } \operatorname { s i g n } \left(V _ { m } \operatorname { s i n } \left(\omega t+\phi_{m}+(i-1) \Delta \phi\right.\right.\right. \\
& \left.+[i+j-2]_{N} \Delta \psi\right)-V_{C}\left(\omega_{s} t+{ }^{\omega_{s}}((i-1) \Delta \phi\right. \\
& \left.\left.\left.\left.+[i+j-2]_{N} \Delta \psi\right)\right)\right)-\sum_{j=1}^{N} X_{b}^{(i, j)}\right) \\
= & I_{d c}\left(\sum _ { k = 0 } ^ { N - 1 } \operatorname { s i g n } \left(V _ { m } \operatorname { s i n } \left(\omega t+\phi_{m}+(i-1) \Delta \phi\right.\right.\right. \\
& +k \Delta \psi))-V_{C}\left(\omega_{s} t+{ }_{s}((i-1) \Delta \phi+k \Delta \psi)\right) \\
& \left.-\sum_{j=1}^{N} X_{b}^{(i, j)}\right)
\end{aligned}
$$

Therefore

$$
\mathrm{i}_{\mathrm{a}}^{(\mathrm{i}+1)}(\omega \mathrm{t})=\mathrm{i}_{\mathrm{a}}^{(\mathrm{i})}(\omega \mathrm{t}+\Delta \phi)
$$

That means that secondary side currents of transformer $i$ is shifted from secondary side currents of transformer (i+1) by angle $\Delta \phi$. Further the phase current of secondary side of each transformer is a sum of $\mathrm{N}$ evenly phase shifted currents from $\mathrm{N}$ converters in one the same row. Therefore $\mathrm{N} \times \mathrm{N}$ converter array is equivalent to $6 \mathrm{~N}^{2}$ pulse number converter. Current harmonics in ac side is considerably reduced.

$D C$ side voltage of a converter $\operatorname{Conv}(i, j)$ is

$$
\begin{aligned}
u_{d c}^{(i, j)} & =Y_{a}^{(i, j)} u_{a}^{(i)}+Y_{b}^{(i, j)} u_{b}^{(i)}+Y_{c}^{(i, j)} u_{c}^{(i)} \\
& =-\frac{1}{2}\left(X_{a}^{(i, j)} v_{c a}^{(i)}+X_{b}^{(i, j)} v_{a b}^{(i)}+X_{c}^{(i, j)} v_{b c}^{(i)}\right)
\end{aligned}
$$

and 
Sum of DC side voltage of a column of converters is $\mathfrak{u}_{\mathrm{dc}}^{(\mathrm{j})}$

$$
\begin{aligned}
u_{d c}^{(j)} & =\sum_{i=1}^{N} u_{d c}^{(i, j)} \\
& =-\frac{1}{2} \sum_{i=1}^{N}\left(X_{a}^{(i, j)} v_{c a}^{(i)}+X_{b}^{(i, j)} v_{a b}^{(i)}+X_{c}^{(i, j)} v_{b c}^{(i)}\right.
\end{aligned}
$$

The dc component of $u_{d c}^{(j)}$ is

$$
\begin{aligned}
\mathrm{U}_{\mathrm{dc}}^{(j)} & ={ }_{2 \pi}^{1} \int_{0}^{2 \pi} \mathrm{u}_{\mathrm{dc}}^{(\mathrm{j})} \mathrm{d} \omega \mathrm{t} \\
& =-\frac{-3}{2} \sum_{\mathrm{i}=1}^{\mathrm{N}} \int_{0}^{2 \pi} \mathrm{X}_{\mathrm{a}}^{(\mathrm{i}, \mathrm{j})} \mathrm{v}_{\mathrm{ca}}^{(\mathrm{i})} \mathrm{d} \omega \mathrm{t} \\
& =-3 \sum_{\mathrm{i}=1}^{\mathrm{N}} \int_{0}^{2 \pi} \operatorname{sign}\left(\mathrm { V } _ { \mathrm { m } } \operatorname { s i n } \left(\omega \mathrm{t}+\phi_{\mathrm{m}}\right.\right. \\
& \left.+(\mathrm{i}-\mathrm{l}) \Delta \phi+[\mathrm{i}+\mathrm{j}-2]_{\mathrm{N}} \Delta \psi\right) \\
& \left.-\mathrm{V}_{\mathrm{c}}\left(\omega_{\mathrm{s}} \mathrm{t}+{ }^{\omega_{\mathrm{s}}}\left((\mathrm{i}-1) \Delta \phi+[\mathrm{i}+\mathrm{j}-2]_{\mathrm{N}} \Delta \psi\right)\right)\right) \\
& \sqrt{3} \mathrm{U} \sin \left(\omega \mathrm{t}-240^{0}+30^{0}+(\mathrm{i}-1) \Delta \phi\right) \mathrm{d} \omega \mathrm{t} \\
& =\frac{-3}{2} \sum_{\mathrm{k}=0}^{\mathrm{N}-1} \int_{0}^{2 \pi} \operatorname{sign}\left(\mathrm{V}_{\mathrm{m}} \sin \left(\omega \mathrm{t}+\phi_{\mathrm{m}}+\mathrm{k} \Delta \psi\right)\right. \\
& \left.-\mathrm{V}_{\mathrm{c}}\left(\omega_{\mathrm{s}} \mathrm{t}+\frac{\omega_{\mathrm{s}}}{\omega} \mathrm{k} \Delta \psi\right)\right) \sqrt{3} \mathrm{U} \sin \left(\omega \mathrm{t}-210^{0}\right) \mathrm{d} \omega \mathrm{t}
\end{aligned}
$$

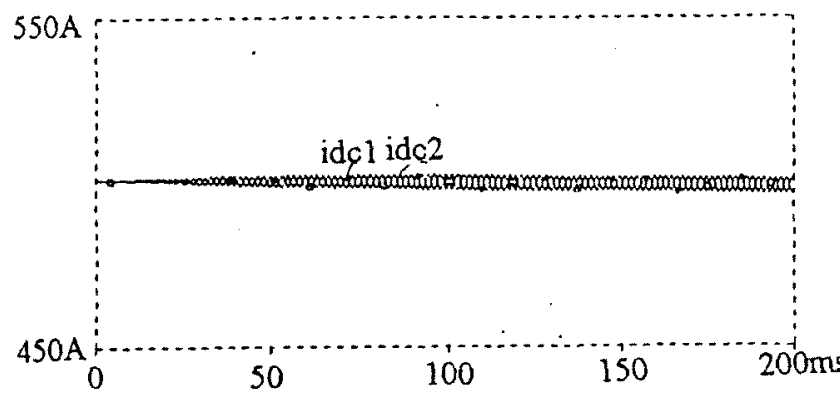

Figure 6: two columns automatically share the current of superconducting magnetic coil

$U_{\mathrm{dc}}^{(\mathrm{j})}$ is independent of $\mathrm{j}$. Therefore average voltage of each column of converters is the same. It is means that paralleling of output side of columns of converters is possible. Fig. 6 shows de side output currents of two columns of converters in $2 \times 2$ converter array when no current sharing control is used. DC side currents are automatically balanced.

\section{Harmonic characteristics of converter array}

A $2 \times 2$ converter array used in SMES is shown in Fig.7.

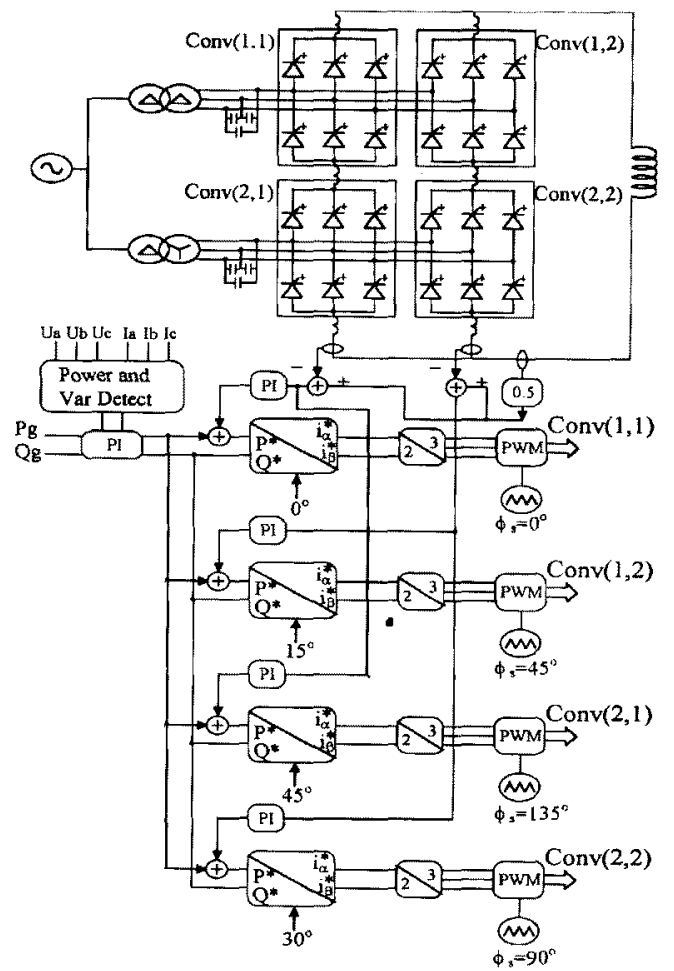

Figure 7: SMES using converter array

A $\Delta / \Delta$ transformer and a $\Delta / Y$ transformer is used to generate phase shifted ac voltages. Phase shift $\Delta \phi=30^{\circ}$. The inter-phase reactors are $0.1 \mathrm{H}$. Its modulation signals and carrier signals are arranged as shown in Fig.7. Fig.8. shows $\mathrm{AC}$ side current of the converter array. Fig. 9 and Fig. 10 show a phase current on utility line and its spectrum. The inductance of superconducting magnetic coil $L_{S M C}$ is $40 \mathrm{H}$. The initial current of it is $1000 \mathrm{~A}$. The amplitude of the phase voltage of the utility is $1000 \mathrm{~V}$. The carrier frequency is $150 \mathrm{~Hz}$ and utility frequency is $50 \mathrm{~Hz}$. Two transformers are used to eliminate 5 th and 7th harmonic. 11th and 13th is considerably reduced through phase shifting of both carrier and modulation signal among converters. DC voltage unbalance is overcome by serially connected DC side of two converter.

For comparison Fig.11 and Fig.12 shows one phase current of conventional direct paralleled four converters. Carriers for these four converters are evenly shifted by $45^{\circ}$ to eliminate $6 n \pm 1$ harmonics where $n=1,2$, and 3 . Modulation signal amplitudes are controlled to evenly share SMES coil current. The initial energy of $L_{S M C}$ is the same as that of the $2 \times 2$ converter array. The initial current of the superconducting magnetic coil is selected to be $2000 \mathrm{~A}$ so that the current capacity of each 
converter modular is the same as that of each converter modular of $2 \times 2$ converter array. At this time $L_{S M C}=10 \mathrm{H}$. From Fig, 11 and 12 it can be found that both amplitudes and phases of modulation waves are varied and they are not the same any more. As a result harmonics can not be eliminated each other effectively. There are 5th, 7th, 11th, 13th, 17th, and 19th harmonic current components.

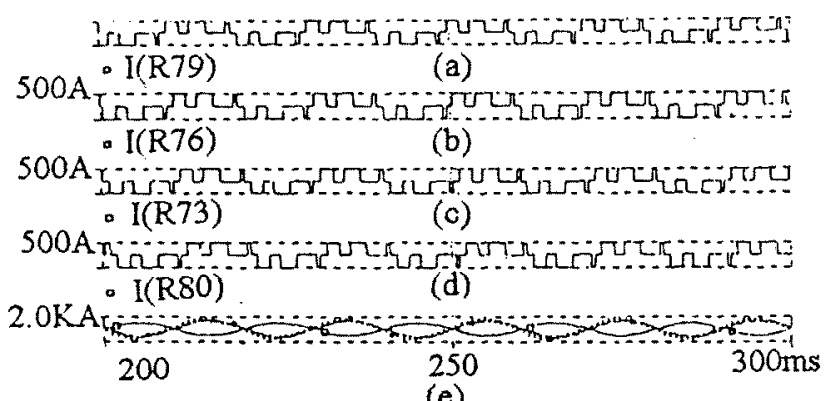

Figure 8: $\mathrm{AC}$ side currents of $2 \times 2$ converter array (a) phase $\mathrm{A}$ current of $\mathrm{AC}$ side of modular converter Conv $(1,1)$ (b) phase A current of Ac side of modular converter Con $(1,2)$ (c) phase A current of Ac side of modular converter Con $(2,1)$ (d) phase A current of Ac side of modular converter Con $(2,2)$ (e) phase A voltage and current of $\mathrm{AC}$ side of the converter array
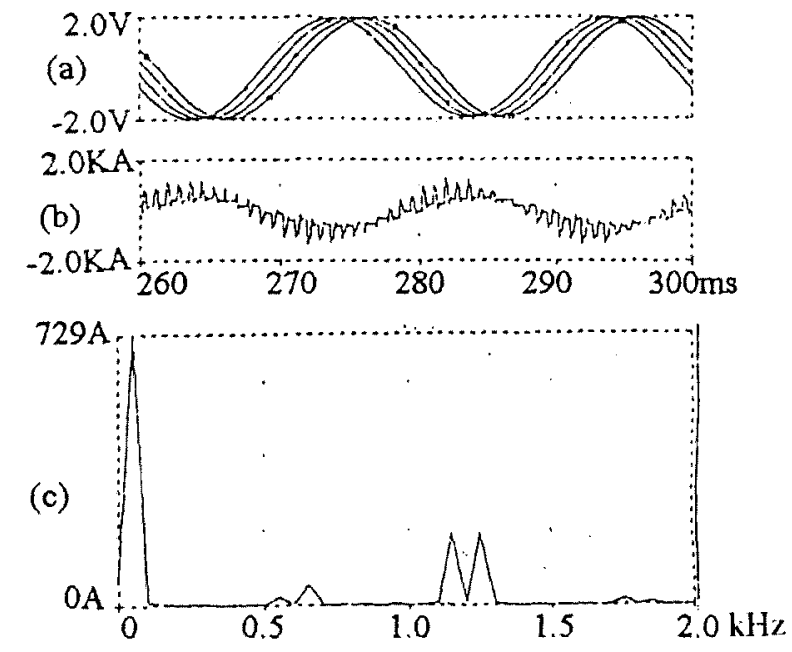

Figure 9: $2 \times 2$ converter array with $\mathrm{P}=-1 \mathrm{MW}$ and $\mathrm{Q}=$ $-0.5 \mathrm{MVar}$ (a) phase A modulation signals of four converters (b) a phase current (c) harmonic spectrum of a phase current

(a)

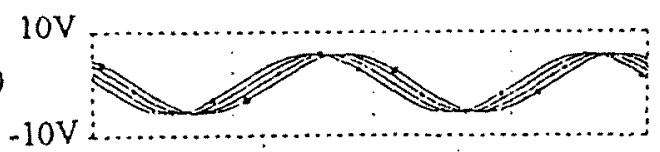

2.0KA:

(b)
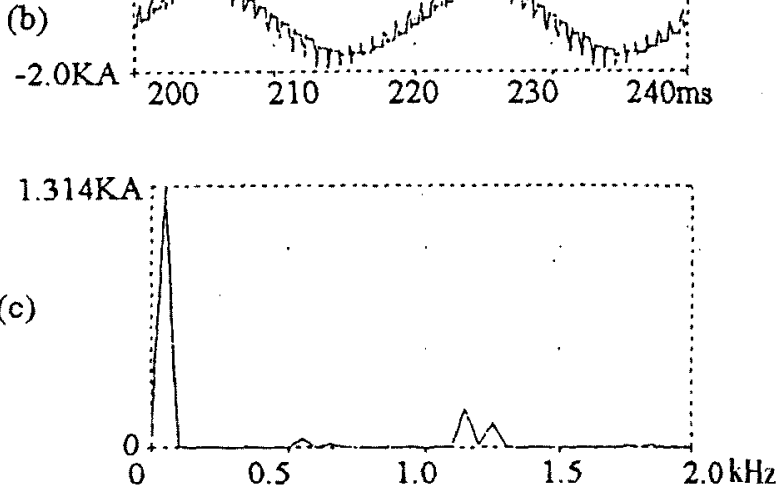

Figure 10: $2 \times 2$ converter array with $\mathrm{P}=-2 \mathrm{MW}$ and $\mathrm{Q}=0 \mathrm{MVar}$ (a) phase A modulation signals of four converters (b) a phase current $\quad(c)$ harmonic spectrum of a phase current

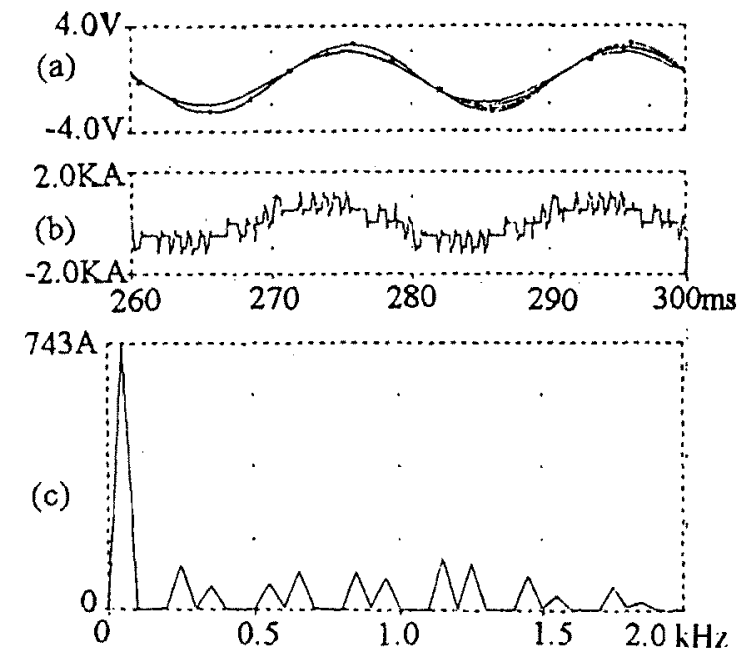

Figure 11: direct paralleled four converters with $\mathrm{P}=-$ $1 \mathrm{MW}$ and $\mathrm{Q}=-0.5 \mathrm{MVar}$ (a) phase $\mathrm{A}$ modulation signals of four converters (b) a phase current (c) harmonic spectrum of a phase current

New proposed converter array has less low frequency harmonics than the conventional direct paralleled converter structure. $2 \times 2$ array converter is approximate to a 24 pulse number converter in respect to reduction of harmonics. 


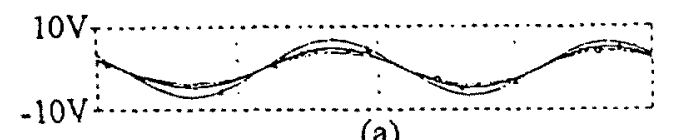

(a)

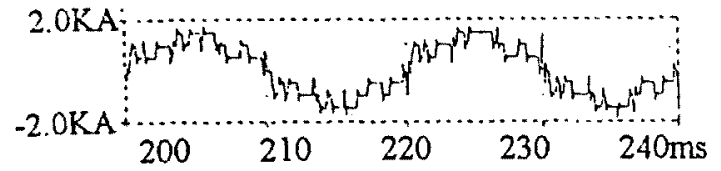

(b)

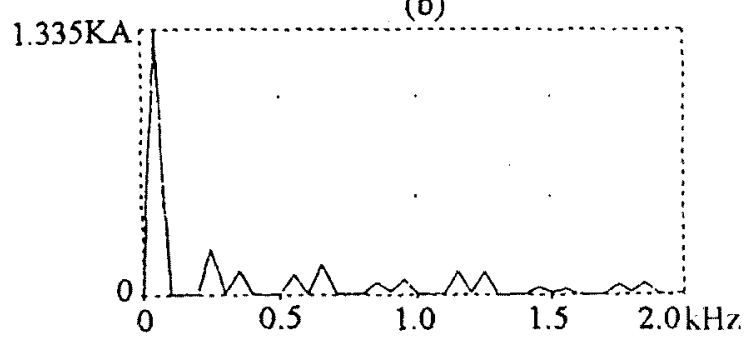

(c)

Figure 12: direct paralleled four converters with $\mathrm{P}=$ $2 \mathrm{MW}$ and $\mathrm{Q}=0 \mathrm{MVar}$ (a) phase $\mathrm{A}$ modulation signals of four converters (b) a phase current (c) harmonic spectrum of a phase current

\section{SMES using $2 \times 2$ converter array}

The proposed converter is able to work at full $\mathrm{P}-\mathrm{Q}$ plane. It can generate both active power and reactive power.

\subsection{Active and reactive power control}

By using the new converter shown in Fig.5 active power and reactive power control is carried out. Fig.13 shows power tracking process. Fig.13(a) shows voltage and current of phase A of the converter array. Fig.13(b) gives power and reactive power generated by the converter array. Fig.13(c) shows decaying current of the superconducting magnetic coil $\mathrm{L}_{S M C}$ because of discharge of magnetic energy.

\subsection{Maximum power}

The upper limit power which can be output by a $\mathrm{N} \times \mathrm{N}$ converter array can be estimated as

$$
P_{\max }=\mathrm{N}^{2} \times \mathrm{U}_{\mathrm{dc} \max } \mathrm{I}_{\mathrm{dc}}
$$

where $U_{d c \max }$ is maximum value of $\mathrm{DC}$ side average voltage of a converter module and $I_{\mathrm{dc}}$ is $\mathrm{DC}$ side average current of a converter module. In addition $I_{d c}=I_{s m c} / N$ and $I_{s m c}$ is the current of superconducting magnetic coil. $\mathrm{U}_{\mathrm{dc} \max }$ is able to be calculated as

$$
\mathrm{U}_{\mathrm{dc} \max }=1.65 \mathrm{U}_{\mathrm{am}}
$$

where $U_{a m}$ is the amplitude of the phase voltage of the utility. Therefore

$$
\mathrm{P}_{\max }=1.65 \mathrm{NU}_{\mathrm{am}} \mathrm{I}_{\mathrm{smc}}
$$

For the $2 \times 2$ converter array shown in Fig.7, maximum power can be estimated by

$$
P_{\max }=1.65 \times 2 \times 1000 \mathrm{~V} \times 1000 \mathrm{~A}=3.3 \mathrm{MW}
$$

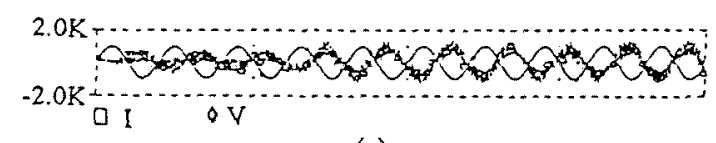

(a)

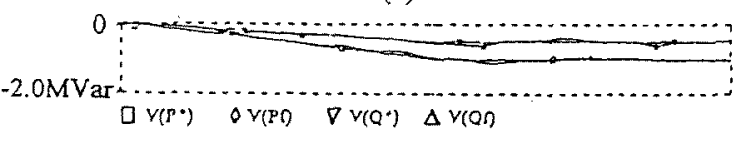

(b)

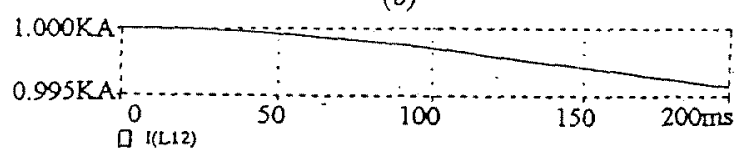

(c)

Figure 13: Active power and reactive power control process (a) phase voltage and current of $\mathrm{AC}$ side of the converter array (b) active and reactive powers generated by the converter array (c) the current of $\mathrm{L}_{\mathrm{SMC}}$
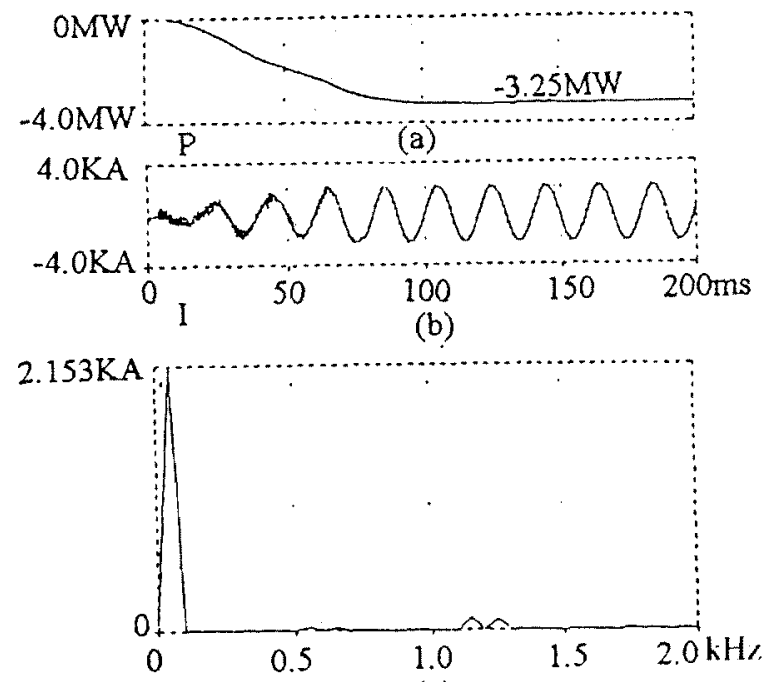

(c)

Figure 14: $2 \times 2$ converter array in maximum power output state (a) maximum power (b) a line current (c) its spectrum 

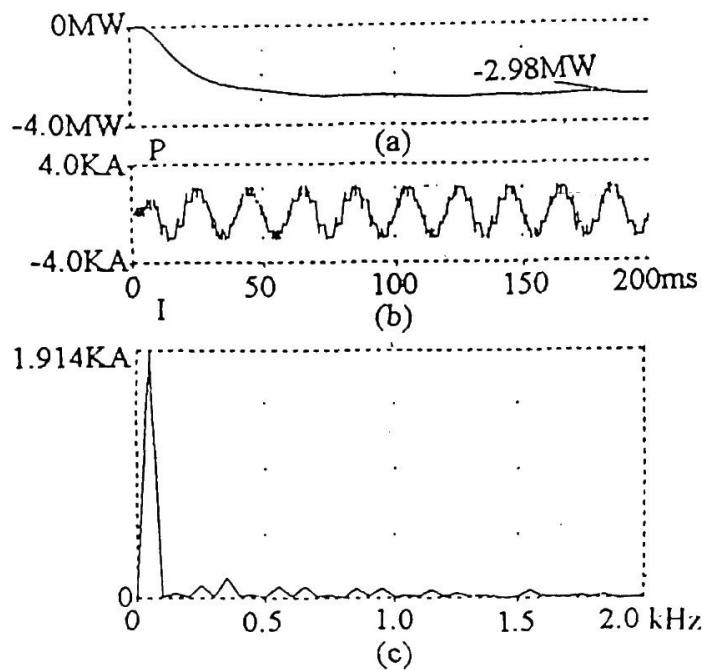

Figure 15: direct paralleled four converters in maximum power output state (a) maximum power (b) a line current (c) its spectrum

Since there exist phase shifting among modulation signals in the same row of a $\mathrm{N} \times \mathrm{N}$ converter array, it is impossible to force all converters at the same row to output maximum voltages. Maximum power a converter array can output is always less than the upper limit value given above. Fig.14(a) shows maximum power which can be output by the $2 \times 2$ converter array. Fig. 14(b) and (c) shows a line current and its spectrum. For comparison Fig.15(a) shows maximum power which can be output by direct paralleled four converters. Fig.15(b) and (c) show a line current and its spectrum. It means that capacity of the switching devices in the converter array are effectively used.

\section{Conclusion}

GTO current source converter array with appropriate arrangement of modulation and carrier signals can output large power with high quality current waveform. $A \mathrm{~N} \times \mathrm{N}$ converter array is similar to a $6 \mathrm{~N}^{2}$ pulse number converter in respect to harmonic performance. low switching of GTO is required since PWM is primarily used as a method to control flow of power instead of reducing harmonics. The capacity of the switching devices in the converter array is effectively used.

(Manuscript received May 23, '97, rivised Sep. 22, '97)

\section{References}

[1] Z. Zhang, B. T. Ooi, "multi modular current source SPWM converters for superconducting magnetic energy storage system", IEEE Trans. PE. Vol.8, No.3, pp250-256, July, 1993.

[2] M. Nakade, T. Ise, Y.Murakami, "Multi-parallel configuration of a current source $\mathrm{AC} / \mathrm{DC}$ converter with energy recovery snubber circuits", power electronics symposium record, IEEJ,Vol.20,No.1, 1994.

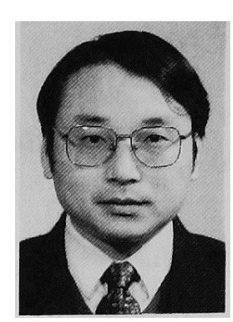

Dehong Xu (member) He was born in Hangzhou, China in 1961. He received BS. degree and MS. and $\mathrm{Ph}$. D degrees in 1983, 1986, and 1989 respectively from the Department of Electrical Engineering of Zhejiang University, China. He was a visiting

scholar of the University of Tokyo University from June of 1995 to May of 1996. In 1996 he became a professor at the Department of Electrical Engineering of Zhejiang University. He present interest is power electronics and large power converter for SEMS. He is a member of IEEE and IEEJ.

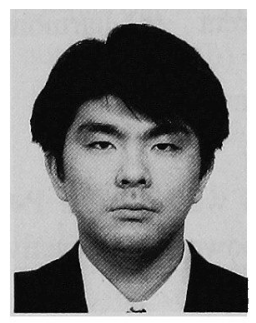

Baba Junpei (student member) He was born in Kanagawa in 1973. $\mathrm{He}$ received $\mathrm{BS}$. degree in the Department of Electrical Engineering of the University of Tokyo in 1996. He is presently a postgraduate student studying towards MS. in the

Department of Electrical Engineering of the University of Tokyo. His present interest is power electronics and its control. He is a member of IEEJ.

Masada Eisuke (member) He was born in Chiba in 1937. He received D. Eng. degree from the University of Tokyo in 1965. In 1987 he became a professor in the Department of Electrical Engineering of the University of Tokyo. He is present interest regards electrical machines and control systems. In 1997 he became the chairman of IEEJ. He is a member of IEEE, VDE, TRB, and Japanese Academy of Engineering.

Ohsaki Hiroyuki (member) He was born in Hokkaido, in 1961. He received D. Eng. degree from the University of Tokyo in 1988. In 1993 he became an associate professor in the Department of Electrical Engineering of the University of Tokyo. His present interest is linear drive systems and application of HTc super-conductors. He is a member of IEEE and IEEJ. 